\section{Diabetes and Obesity - Inextricable Diseases}

\author{
Massiell German ${ }^{1}$ and Juliana Simonetti ${ }^{2 *}$ \\ ${ }^{1}$ Department of Diabetes, Endocrinology and Metabolism, University of Utah, \\ Salt Lake City Utah, USA \\ ${ }^{2}$ Department of Diabetes, Endocrinology Metabolism and Department of \\ Surgery, University of Utah, Salt Lake City, Utah, USA
}

\begin{abstract}
Diabetes and obesity are global epidemics and the prevalence of both has increased in parallel. The relationship between obesity and diabetes is clear as nearly $90 \%$ of people with diabetes have obesity. Multiple factors contribute to obesity and include dietary, environmental and iatrogenic causes all of which can affect metabolism directly and independently of caloric intake alone. Studies focused on the pathophysiology of the relationship between diabetes and obesity has led to innovations in diabetes care with a focus on obesity. Weight loss is now recommended in all patients with diabetes and adjuvant pharmacological and surgical therapies are available and often recommended, to supplement lifestyle changes for weight loss. Diabetes claims the lives of hundreds of thousands of people every year and the financial burden of diabetes is staggering at over 200 billion dollars annually. Control of obesity is imperative in controlling diabetes.
\end{abstract}

Keywords: Diabetes; Hormones; Obesity; Weight loss

\section{Introduction}

The relationship between type 2 diabetes and obesity has been demonstrated repeatedly in recent decades. Currently the prevalence of obesity in adults in the United States is $39.8 \%$ and of these 34 million people, $89 \%$ have overweight or obesity. The prevalence of diabetes and obesity is also on the rise worldwide. Globally, there are 422 million people with diabetes and 1.9 billion people with overweight or obesity $[1,2]$. This represents a quadrupling and tripling of diabetes and overweight or obesity respectively in the last 50 years $[1,2]$. Although there has been great advancement in pharmacological therapy for treatment of diabetes, only half of those with diabetes have HgbA1c at goal of less than 7.0\% [3]. Uncontrolled diabetes is

${ }^{\star}$ Corresponding author: Juliana Simonetti, Department of Diabetes, Endocrinology Metabolism, and Department of Surgery, University of Utah, Salt Lake City, Utah, USA, Tel: +1 2038205815; E-Mail: juliana.simonetti@hsc.utah.edu

Citation: German M, Simonetti J (2020) Diabetes and Obesity - Inextricable Diseases. J Diabetes Metab Disord 7: 036.

Received: November 16, 2020; Accepted: November 19, 2020; Published: November 26, 2020

Copyright: (c) 2020 German M, et al. This is an open-access article distributed under the terms of the Creative Commons Attribution License, which permits unrestricted use, distribution, and reproduction in any medium, provided the original author and source are credited. associated with micro vascular (nephropathy, neuropathy and retinopathy) and macro vascular (stroke, myocardial infarction, peripheral arterial disease) complications. Over a third of patients with diabetes have chronic kidney disease and tens of thousands of patients with diabetes undergo lower extremity amputations every year. Diabetic retinopathy is the leading cause of blindness in the United States. The National Diabetes Statistics Report 2020 estimates over 1.5 million people with diabetes were hospitalized for ischemic heart disease or stroke in 2016. These complications are a massive financial burden. The direct cost of diabetes is over 200 billion dollars annually and has increased by almost 50 billion dollars in the last five years [3]. Ultimately, despite current efforts to treat diabetes and prevent complications, it is the seventh leading cause of death in the United States. In 2017 alone, diabetes was listed as the underlying or contributing cause of death of over 250,000 people $[3,4]$.

\section{Why the weight gain}

The reasons for weight gain are multifactorial and caused by a complex interplay between genetics and the environment [5]. It is rare that a person with obesity or overweight has not attempted a diet and exercise plan. Despite these attempts, only about $50 \%$ of people are able to maintain weight loss for 1 year [6]. While obesity is ultimately the result of more calories consumed than burned, the reasons for this persistent discrepancy are complex. Genetics play a significant role in Body Mass Index (BMI) variance and in response to the environment, namely food intake and physical activity. Studies in twins have demonstrated that $50-70 \%$ of the BMI variance may be explained by genetics [7]. Human genetic studies using the genome-wide association approach have revealed severe monogenic forms of obesity such as congenital leptin deficiency and melanocortin-4 receptor deficiency $[8,9]$. Genetics alone however cannot explain the increased incidence of obesity in recent decades. There is a natural drive for food consumption and pleasure is derived from eating, an adaptation that has ensured our survival. Animal studies have long suggested that dopamine is involved in mediating feeding behavior as rats in which the dopaminergic neurons were destroyed developed aphagia and died within a week [10]. Palatable foods, especially those high in sugar and fat, elevate dopamine levels in the nucleus accumbens of the ventral striatum, an important part of the reward pathway $[11,12]$. The pleasurable effect of food is a motivating factor that can override homeostatic signals [13-15]. A predilection for high sugar and high fat foods has not gone unnoticed by the food and entertainment industries. High sugar and calorically dense foods are more readily available, cheaper and often in larger portions than more nutritious and lower calorie foods [16,17]. Accessibility to palatable energy-dense foods is a major risk factor for obesity [18]. The average American today consumes more than 500 calories daily from added sugar alone which is found in suspected sources like soda but also in presumed healthier options like salad dressing, granola and yogurt [19]. Not only are highly palatable foods rewarding, but individuals with obesity experience greater reward from food as compared to their lean counterparts. This was shown in a study using Functional Magnetic Resonance Imaging (FMRI) looking at activation of the gustatory cortex and in 
somato sensory regions of the brain in response to anticipated intake of a chocolate milkshake (vs. a tasteless solution) and to actual consumption of milkshake (vs. a tasteless solution) [20]. As more calories are being consumed, fewer calories are being burned. With technological advancements, work and leisure time are comprised of more sedentary activities which leads to decreased energy expenditure. A sedentary lifestyle can also cause physiological changes which lead to decreased resting metabolic rate such as decreased mitochondrial functionality and decreased lean muscle mass [21]. Iatrogenic contributors are often overlooked; beta blockers, antidepressants, glucocorticoids, injectable progestin's, antipsychotics and antiepileptic drugs are all associated with weight gain $[22,23]$. In addition, anti-diabetes medications themselves, including insulin and sulfonylureas, can cause weight gain [24].

\section{Pathophysiology of obesity and diabetes}

The body manages a discrepancy between calories consumed and burned by storing the energy as fat in adipocytes. While functioning as an energy source, these cells comprise an endocrine organ which produces hormones responsible for regulating insulin sensitivity, appetite and energy balance. Increased fat mass increases serum free fatty acids which stimulates insulin secretion from pancreatic beta cells while causing insulin resistance of skeletal muscle. Insulin resistance leads to elevated blood glucose and further insulin secretion. Elevated insulin level elicits insulin resistance in the liver and adipose tissue which then also contributes to the cycle of elevated blood glucose and insulin secretion. Elevated blood glucose causes a state of constant pancreatic beta cell stimulation and diabetes develops when the pancreas is unable to meet insulin demand resulting in hyperglycemia. Hormones produced by adiposities, like leptin and asprosin, are increased in obesity. In normal circumstances, leptin inhibits insulin production, increases skeletal muscle metabolism of glucose and inhibits hepatic glucose production. However, in patients with obesity, resistance to leptin develops, thereby leading to worsening hyperglycemia due to uninhibited insulin production, decreased skeletal glucose metabolism and increased hepatic glucose production. Obesity does not seem to induce resistance to asprosin, a recently identified adipose hormone that stimulates hepatic glucose production and peaks during fasting thereby causing hyperglycemia even in the absence of additional glucose and fatty acid consumption. Ultimately hyperglycemia results in beta cell death and exogenous insulin dependence $[25,26]$.

\section{Weight loss as treatment for diabetes}

Effective diabetes treatment is multifaceted and lifestyle modification is essential for diabetes control. The American Diabetes Association (ADA) recommends 5\% weight loss in all patients with type 2 diabetes [22]. Weight loss in those with diabetes is uniquely challenging as many of the medications used to treat diabetes, in particular the older classes, also cause weight gain. Some studies suggest that patients can gain as much as $10 \mathrm{~kg}$ in a relatively short period (3 to 6 months) after initiating treatment with insulin, sulfonylureas, and other insulin secretagogues like glitinides and thiazolidinediones $[24,27]$. Medications like sulfonylureas and insulin work by filling the gap between insulin required for adequate cellular glucose transport and insulin actually produced. Glucose that would have otherwise remained in serum is then available for metabolism and fat storage which contributes to insulin resistance. Metformin as well as newer classes of diabetes medications such as Glucagon like Peptide-1
(GLP-1) receptor agonists, dipeptidyl peptidase-4 inhibitors and sodium-glucose co-transporter 2 inhibitors are weight neutral or can lead to weight loss [28]. As such, their use is preferred prior to considering weight promoting anti-glycemic medications like insulin. Trials comparing GLP-1 agonists and other anti hyperglycemic agents have shown weight loss in some subjects ranging between 5.5 and 8 $\mathrm{kg}$. Metformin and SGLT-2 inhibitors produce more modest weight loss, in the 1 to $3 \mathrm{~kg}$; these agents have not been studied in the setting of concomitant behavioral therapy, and the full weight loss potential is therefore not yet known [27]. The ADA recommends the use of pharmacological weight loss therapies (e.g. liraglutide, phentermine, phentermine/topiramate, naltrexone/bupropion) for treatment of obesity in diabetics with BMI 27 and greater. In patients with BMI > 40 and diabetes, the ADA recommends bariatric surgery [22]. These recommendations highlight the importance of managing obesity in the treatment of diabetes given the dual benefit of weight loss and glycemic control.

While most trials in the United States have focused on preventing diabetes with weight loss from lifestyle changes [29,30], a trial in Scotland and the United Kingdom has evaluated the effect of significant weight loss from lifestyle changes in people with a diagnosis of diabetes [31]. In this study all diabetes medications were discontinued on initiation of a restricted calorie diet and increase in physical activity. At 12 months, 149 participants had completed the study; 24\% reached goal weight loss of $15 \mathrm{~kg}$ with mean weight loss of $10 \mathrm{~kg}$ and HgbAlc decreased by an average of $0.9 \%$. While standard protocols for blood glucose monitoring and diabetes drug reintroduction were in place, at 12 months $74 \%$ of participants were off all diabetes medications. This study demonstrates that diabetes remission is obtainable with weight loss from lifestyle changes alone. However, weight loss must be maintained in order to maintain remission and this is arguably a greater challenge than weight loss itself. Several factors contribute to weight gain following weight loss. In addition to the difficulty of maintaining behavioral changes, physiological changes that occur with weight loss may also contribute to weight gain. Resting energy expenditure decreases with reduced body weight and several studies suggest this decrease in resting energy expenditure is greater than would be expected for decrease in body mass [32-34]. Simultaneously, hormonal changes that occur with weight loss, including increase in ghrelin and gastric inhibitory peptide, stimulate hunger and may promote energy storage $[35,36]$. Hormones that inhibit appetite and food intake, including pancreatic polypeptide, peptide YY, cholecystokinin, glucagon-like peptide and amylin, decrease with weight loss [37-42] and these changes were found to persist at a year after weight loss [34]. One study performed to quantify whether and to what extent appetite counters weight loss found that weight loss results in an increased caloric consumption of $100 \mathrm{kcal}$ per day per $\mathrm{kg}$ of weight lost [42]. The changes in resting energy expenditure and hormonal changes that occur with weight loss contribute to the plateau effect which may discourage people with obesity from continuing their efforts to lose weight $[35,43]$. Several studies have suggested that hormonal changes that contribute to weight gain are altered with bariatric surgery [44]. Roux-en-Y gastric bypass, one of the most common and effective bariatric surgeries, has been associated with decreased ghrelin and increased cholecystokinin, peptide YY and postprandial GLP-1 levels [45-48]. Weight loss with bariatric surgery is superior to that obtained via lifestyle changes and/or medical therapy and these hormonal changes likely contribute to this success [49]. 


\section{Conclusion}

Successful treatment of diabetes must include concurrent treatment of obesity and overweight. Lifestyle and behavioral changes are necessary to combat a modern society in which addictive energy sources are abundant and readily obtainable with little energy expenditure. However, treatment of obesity is not as simple as calories in, calories out. Weight loss leads to physiological changes that perhaps for the first time in human history are maladaptive. Adjuvant medical and surgical therapies are recommended to overcome these barriers to weight loss and treat diabetes.

\section{References}

1. Roglic G (2016) WHO Global report on diabetes: A summary. International Journal of Noncommunicable Diseases 1: 3-8.

2. World Health Organization (2020) Obesity and Overweight. Geneva, Switzerland.

3. Centers for Disease Control and Prevention (2020) National diabetes statistics report, 2020. Centers for Disease Control and Prevention, Atlanta, USA.

4. Hales CM, Carroll MD, Fryar CD, Ogden CL (2017) Prevalence of obesity among adults and youth: United States, 2015-2016. NCHS Data Brief 288: $1-8$.

5. Temelkova-Kurktschiev T, Stefanov T (2011) Lifestyle and genetics in obesity and type 2 diabetes. Exp Clin Endocrinol Diabetes 120: 1-6.

6. Curioni CC, Lourenco PM (2005) Long-term weight loss after diet and exercise: A systematic review. Int J Obes (Lond) 29: 1168-1174.

7. Allison DB, Kaprio J, Korkeila M, Koskenvuo M, Neale MC, et al. (1996) The heritability of body mass index among an international sample of monozygotic twins reared apart. Int J Obes Relat Metab Disord 20: 501506.

8. Farooqi IS, Keogh JM, Yeo SHG, Lank EM, Cheetham T, et al. (2003) Clinical spectrum of obesity and mutations in the melanocortin 4 receptor gene. N Engl J Med 348: 1085-1095.

9. Montague CT, Farooqi IS, Whitehead JP, Soos MA, Rau H, et al. (1997) congenital leptin deficiency is associated with severe early-onset obesity in humans. Nature 387: 903-908.

10. Ungerstedt U (1971) Adipsia and aphagia after 6-hydroxydopamine induced degeneration of the nigro-striatal dopamine system. Acta Physiol Scand Suppl 367: 95-122.

11. Leigh SJ, Morris MJ (2018) The role of reward circuitry and food addiction in the obesity epidemic: An update. Biol Psychol 131: 31-42.

12. Lennerz B, Lennerz JK (2018) Food Addiction, High-Glycemic-Index Carbohydrates, and Obesity. Clin Chem 64: 64-71.

13. Shomaker LB, Zocca JM, Courville A, Kozlosky M, Ali AH, et al. (2010) Eating in the absence of hunger in adolescents: intake after a large-array meal compared with that after a standardized meal. Am J Clin Nutr 92: 697-703.

14. Sunday SR, Sanders SA, Collier G (1983) Palatability and meal patterns Physiol Behav 30: 915-918.

15. Zheng H, Lenard N, Shin AC, Berthoud HR (2009) Appetite control and energy balance regulation in the modern world: reward-driven brain overrides repletion signals. Int J Obes (Lond) 33: 8-13.

16. Hill JO, Wyatt HR, Reed GW, Peters JC (2003) Obesity and the environment: where do we go from here? Science 299: 853-855.

17. Swinburn B, Sacks G, Ravussin E (2009) Increased food energy supply is more than sufficient to explain the US epidemic of obesity. Am J Clin Nutr 90: $1453-1456$
18. Volkow ND, Wise RA (2005) how can drug addiction help us understand obesity? Nat Neurosci 8: 555-560.

19. Lustig RH, Schmidt LA, and Brindis C (2012) Public health: The toxic truth about sugar. Nature 482: 27-29.

20. Stice E, Spoor S (2008) Relation of reward from food intake and anticipated food intake to obesity: a functional magnetic resonance imaging study. J Abnorm Psychol 117: 924-935.

21. Lavie CJ, Ozemek C, Carbone S, Katzmarzyk PT, Blair SN (2019) Sedentary Behavior, Exercise, and Cardiovascular Health. Circ Res 124: 799815.

22. Association AD (2020) Standards of Medical Care in Diabetes-2020. Diabetes Care 43: S193-S202.

23. Williams B (2007) the obese hypertensive: the weight of evidence against beta-blockers. Circulation 115: 1973-1984.

24. Intensive blood-glucose control with sulphonylureas or insulin compared with conventional treatment and risk of complications in patients with type 2 diabetes (UKPDS 33). UK Prospective Diabetes Study (UKPDS) Group. Lancet 352: 837-53.

25. Chen W, Balland E, Cowley MA (2017) Hypothalamic Insulin Resistance in Obesity: Effects on Glucose Homeostasis. Neuroendocrinology 104: 364-381.

26. Romere C, Duerrschmid C, Bournat J, Constable P, Jain M, et al. (2016) Asprosin, a Fasting-Induced Glucogenic Protein Hormone. Cell 165: 566579 .

27. Apovian CM, Aronne LJ, Bessesen DH, Ryan DH, Pagotto U, et al. (2015) Pharmacological management of obesity: an endocrine Society clinical practice guideline. J Clin Endocrinol Metab 100: 342-362.

28. Koliaki C, Doupis J (2011) Incretin-based therapy: a powerful and promising weapon in the treatment of type 2 diabetes mellitus. Diabetes Ther 2: $101-121$.

29. Knowler WC, Connor EB, Fowler SE, Hamman RF, Lachin JM, et al (2002) Reduction in the incidence of type 2 diabetes with lifestyle intervention or metformin. N Engl J Med 346: 393-403.

30. Mudaliar U, Zabetian A, Goodaman M, Albright AL, Gregg E, et al. (2016) Cardiometabolic Risk Factor Changes Observed in Diabetes Prevention Programs in US Settings: A Systematic Review and Meta-analysis. PLoS Med. 13: e1002095.

31. Lean ME, Leslie WS, Barnes AC, Brosnahan N, Thom G, et al. (2018) Primary care-led weight management for remission of type 2 diabetes (DiRECT): An open-label, cluster-randomised trial. Lancet 391: 541-551.

32. Fothergill E, Guo J, Howard L, Kerns CJ, Knuth ND, et al. (2016) Persistent metabolic adaptation 6 years after "The Biggest Loser"competition. Obesity (Silver Spring) 24: 1612-1629.

33. Muller MJ, Bosy-Westphal A (2013) Adaptive thermogenesis with weight loss in humans. Obesity (Silver Spring) 21: 218-228.

34. Sumithran P, Shulkes A, Proietto J, Kriketos A, Purcell K, et al. (2011) Long-term persistence of hormonal adaptations to weight loss. $\mathrm{N}$ Engl $\mathrm{J}$ Med 365: 1597-1604.

35. Hauner H, Glatting G, Kaminska D, Pfeiffer EF (1988) Effects of gastric inhibitory polypeptide on glucose and lipid metabolism of isolated rat adipocytes. Ann Nutr Metab 32: 282-288.

36. Wren AM, Seal LJ, Cohen MA, Brynes AE, Frost GS, et al. (2001) Ghrelin enhances appetite and increases food intake in humans. J Clin Endocrinol Metab 86: 5992.

37. Batterham RL, Cowley MA, Small C, Herzog H, Dakin CL, et al. (2002) Gut hormone PYY(3-36) physiologically inhibits food intake. Nature 418: $650-664$. 
38. Batterham RL, Roux CWL, Cohen MA, Park AJ, Ellis SM, et al. (2003) Pancreatic polypeptide reduces appetite and food intake in humans. J Clin Endocrinol Metab 88: 3989-3992.

39. Flint A, Raben A, Astrup A, Holst JJ (1998) Glucagon-like peptide 1 promotes satiety and suppresses energy intake in humans. J Clin Invest 101: 515-520.

40. Gibbs J, Young RC, Smith GP (1997) Cholecystokinin decreases food intake in rats. 1973. Obes Res 5: 284-290.

41. Morley JE, Flood JF (1991) Amylin decreases food intake in mice. Peptides 12: 865-869.

42. Polidori D, Sanghvi A, Seeley RJ, Hall KD (2016) How Strongly Does Appetite Counter Weight Loss? Quantification of the Feedback Control of Human Energy Intake. Obesity (Silver Spring) 24: 2289-2295.

43. Hall KD, Kahan S (2018) Maintenance of Lost Weight and Long-Term Management of Obesity. Med Clin North Am 102: 183-197.

44. Dimitriadis GK, Randeva MS, Miras AD (2017) Potential Hormone Mechanisms of Bariatric Surgery. Curr Obes Rep 6: 253-265.
45. Dirksen C, Jorgensen NB, Bojsen-Moller KN, Kielgast U, Rehfeld JF, et al. (2013) Gut hormones, early dumping and resting energy expenditure in patients with good and poor weight loss response after Roux-en-Y gastric bypass. Int J Obes (Lond) 37: 1452-1459.

46. Evers SS, Sandoval DA, Seeley RJ (2017) the Physiology and Molecular Underpinnings of the Effects of Bariatric Surgery on Obesity and Diabetes. Annu Rev Physiol 79: 313-334.

47. Golzarand MK, Toolabi K, Farid R (2017) The bariatric surgery and weight losing: a meta-analysis in the long- and very long-term effects of laparoscopic adjustable gastric banding, laparoscopic Roux-en-Y gastric bypass and laparoscopic sleeve gastrectomy on weight loss in adults. Surg Endosc 31: 4331-4345.

48. Greenway FL (2015) Physiological adaptations to weight loss and factors favouring weight regain. Int J Obes (Lond) 39: 1188-1196.

49. Colquitt JL, Pickett K, Loveman E, Frampton GK (2014) Surgery for weight loss in adults. Cochrane Database Syst Rev 8: CD003641. 


\section{Hif}

Advances In Industrial Biotechnology | ISSN: 2639-5665

Advances In Microbiology Research | ISSN: 2689-694X

Archives Of Surgery And Surgical Education | ISSN: 2689-3126

Archives Of Urology

Archives Of Zoological Studies | ISSN: 2640-7779

Current Trends Medical And Biological Engineering

International Journal Of Case Reports And Therapeutic Studies | ISSN: 2689-310X

Journal Of Addiction \& Addictive Disorders | ISSN: 2578-7276

Journal Of Agronomy \& Agricultural Science | ISSN: 2689-8292

Journal Of AIDS Clinical Research \& STDs | ISSN: 2572-7370

Journal Of Alcoholism Drug Abuse \& Substance Dependence | ISSN: 2572-9594

Journal Of Allergy Disorders \& Therapy | ISSN: 2470-749X

Journal Of Alternative Complementary \& Integrative Medicine | ISSN: 2470-7562

Journal Of Alzheimers \& Neurodegenerative Diseases | ISSN: 2572-9608

Journal Of Anesthesia \& Clinical Care | ISSN: 2378-8879

Journal Of Angiology \& Vascular Surgery | ISSN: 2572-7397

Journal Of Animal Research \& Veterinary Science | ISSN: 2639-375

Journal Of Aquaculture \& Fisheries | ISSN: 2576-5523

Journal Of Atmospheric \& Earth Sciences | ISSN: 2689-8780

Journal Of Biotech Research \& Biochemistry

Journal Of Brain \& Neuroscience Research

Journal Of Cancer Biology \& Treatment | ISSN: 2470-7546

Journal Of Cardiology Study \& Research | ISSN: 2640-768X

Journal Of Cell Biology \& Cell Metabolism | ISSN: 2381-1943

Journal Of Clinical Dermatology \& Therapy | ISSN: 2378-8771

Journal Of Clinical Immunology \& Immunotherapy | ISSN: 2378-8844

Journal Of Clinical Studies \& Medical Case Reports | ISSN: 2378-880

Journal Of Community Medicine \& Public Health Care | ISSN: 2381-1978

Journal Of Cytology \& Tissue Biology | ISSN: 2378-9107

Journal Of Dairy Research \& Technology | ISSN: 2688-9315

Journal Of Dentistry Oral Health \& Cosmesis | ISSN: 2473-6783

Journal Of Diabetes \& Metabolic Disorders | ISSN: 2381-201X

Journal Of Emergency Medicine Trauma \& Surgical Care | ISSN: 2378-8798

Journal Of Environmental Science Current Research | ISSN: 2643-5020

Journal Of Food Science \& Nutrition | ISSN: 2470-1076

Journal Of Forensic Legal \& Investigative Sciences | ISSN: 2473-733X

Journal Of Gastroenterology \& Hepatology Research | ISSN: 2574-2566
Journal Of Genetics \& Genomic Sciences | ISSN: 2574-2485

Journal Of Gerontology \& Geriatric Medicine | ISSN: 2381-8662

Journal Of Hematology Blood Transfusion \& Disorders | ISSN: 2572-2999

Journal Of Hospice \& Palliative Medical Care

Journal Of Human Endocrinology | ISSN: 2572-9640

Journal Of Infectious \& Non Infectious Diseases | ISSN: 2381-8654

Journal Of Internal Medicine \& Primary Healthcare | ISSN: 2574-2493

Journal Of Light \& Laser Current Trends

Journal Of Medicine Study \& Research | ISSN: 2639-5657

Journal Of Modern Chemical Sciences

Journal Of Nanotechnology Nanomedicine \& Nanobiotechnology | ISSN: 2381-2044

Journal Of Neonatology \& Clinical Pediatrics | ISSN: 2378-878X

Journal Of Nephrology \& Renal Therapy | ISSN: 2473-7313

Journal Of Non Invasive Vascular Investigation | ISSN: 2572-7400

Journal Of Nuclear Medicine Radiology \& Radiation Therapy | ISSN: 2572-7419

Journal Of Obesity \& Weight Loss | ISSN: 2473-7372

Journal Of Ophthalmology \& Clinical Research | ISSN: 2378-8887

Journal Of Orthopedic Research \& Physiotherapy | ISSN: 2381-2052

Journal Of Otolaryngology Head \& Neck Surgery | ISSN: 2573-010X

Journal Of Pathology Clinical \& Medical Research

Journal Of Pharmacology Pharmaceutics \& Pharmacovigilance | ISSN: 2639-5649

Journal Of Physical Medicine Rehabilitation \& Disabilities | ISSN: 2381-8670

Journal Of Plant Science Current Research | ISSN: 2639-3743

Journal Of Practical \& Professional Nursing | ISSN: 2639-568

Journal Of Protein Research \& Bioinformatics

Journal Of Psychiatry Depression \& Anxiety | ISSN: 2573-0150

Journal Of Pulmonary Medicine \& Respiratory Research | ISSN: 2573-0177

Journal Of Reproductive Medicine Gynaecology \& Obstetrics | ISSN: 2574-2574

Journal Of Stem Cells Research Development \& Therapy | ISSN: 2381-2060

Journal Of Surgery Current Trends \& Innovations | ISSN: 2578-7284

Journal Of Toxicology Current Research | ISSN: 2639-3735

Journal Of Translational Science And Research

Journal Of Vaccines Research \& Vaccination | ISSN: 2573-0193

Journal Of Virology \& Antivirals

Sports Medicine And Injury Care Journal | ISSN: 2689-8829

Trends In Anatomy \& Physiology | ISSN: 2640-7752

Submit Your Manuscript: https://www.heraldopenaccess.us/submit-manuscript 